\title{
Activation of primordial follicles in vitro
}

\author{
J. E. Fortune ${ }^{*}$, S. Kito ${ }^{\dagger}$ and D. D. Byrd ${ }^{\ddagger}$ \\ Department and Section of Physiology, College of Veterinary Medicine, Cornell University, \\ Ithaca, NY 14853, USA
}

\begin{abstract}
The resting pool of primordial follicles in mammalian ovaries is a potential resource for the genetic manipulation of domestic animals, the preservation of endangered species, and the amelioration of some forms of infertility in humans. Exploitation of this large reservoir of follicles depends on the development of methods for activating primordial follicles to begin growth in vitro and of methods for sustaining follicular growth to the stage at which oocytes are capable of meiotic maturation, fertilization and development to live young. It has been shown that primordial follicles of rodents, cattle and primates can initiate growth in vitro, even in serum-free medium. The signals that cause primordial follicles to leave the resting pool or remain quiescent are unknown. However, of interest is the observation that in cultures of whole rodent ovaries an apparently normal number of follicles leaves the resting pool and begins to grow, whereas in cultures of isolated bovine or primate ovarian cortex almost all primordial follicles activate and develop into primary follicles. This finding suggests that noncortical portions of the ovary may regulate the flow of follicles from the resting reservoir. In cattle, it has been difficult to sustain follicular growth beyond the primary stage and the development of methods for doing so are critical for achievement of the practical goal of use of the primordial pool for embryo production. However, the development of murine follicles in vitro from the primordial stage through oocyte maturation and fertilization, and the birth of one pup, provides encouragement for efforts to achieve similar results in large mammals.
\end{abstract}

\section{Introduction}

Mammalian ovaries contain a reservoir of non-growing primordial follicles. Primordial follicles are formed when primary oocytes become invested with a layer of flattened pre-granulosal cells. These follicles constitute a pool from which follicles will be drawn gradually to begin growth, starting soon after follicle formation and continuing throughout the reproductive life span. What causes follicles to leave (or remain in) the resting pool and how a continuous 'trickle' of exiting follicles is achieved are unknown. The regulation of follicular quiescence versus growth is currently perhaps the most intriguing question in the area of regulation of ovarian follicular development. Although some progress has been made and will be reviewed in this manuscript, the most fundamental questions remain to be answered.

Two types of mammalian species have been used as models to address questions of the initiation of follicular growth - rodents and larger mammals, especially cattle and primates. In rats and mice follicle formation occurs at a specific time, one or two days after birth, depending on the species or strain. After follicle formation, follicles begin immediately to leave the resting pool and the first cohort reaches the antral stage after about two weeks (Hirshfield, 1991). There are several important advantages to rodents as models for exploring the mechanisms that govern the initiation of follicular growth, a process also referred to as follicle activation. The ovaries of newborn animals are small and

+Current address: NRIS, Division of Education and Scientific Services, 4-9-1 Anagawa, Inage-ku, Chiba 263-8555, Japan †Current address: Cornell University Medical College, 445 E. 69th St, New York, NY 10021 USA 
soft, and they can be cultured as whole ovaries, thus maintaining relationships among ovarian components, or they can be dissociated with enzymes to allow retrieval and culture of individual follicles (see for example Eppig and O'Brien, 1996). In addition the presence of only primordial follicles in newborn rodents allows analysis, during the first few weeks of life, of a synchronous cohort, the first follicles that leave the resting reservoir and initiate growth.

In larger mammals, such as ruminants and primates, the formation of primordial follicles occurs during fetal life over a much more protracted period, compared with that in rodents, of weeks or months (Henricson and Rajakoski, 1959; van Wagenen and Simpson, 1965; Russe, 1983). Some follicles begin to leave the resting pool before others have been formed, so that in these species follicular formation and the initiation of growth are occurring simultaneously within the same ovary. This offers the advantage that fetal ovaries, which may be more readily available and more economical and which have large numbers of primordial follicles, can be used to study follicle growth initiation. However, there are two distinct disadvantages to ruminants and primates as animal models for studies of activation of primordial follicles. First, since some follicles leave the resting pool before other primordial follicles have been formed, there is no easily identifiable time during development when the ovary contains only primordial follicles in large numbers. Second, the stroma of ruminant and primate ovaries is much denser and tougher than the stroma of rodent ovaries, making enzymatic dissociation or mechanical dissection of component parts difficult. This difficulty can be partially obviated by the use of fetal ovaries, which are much softer. However, bovine oocytes are more sensitive to enzymatic treatments that are tolerated well by rodent oocytes and can be easily damaged by enzymatic dissociation of ovarian tissue (Wandji et al., 1996a).

Despite the difficulties of studying the regulation of follicle activation in large mammals, they have been used as models because of the practical benefits that could result from greater knowledge of the signals that regulate follicular growth and differentiation. The resting pool of primordial follicles is a potential resource that could be tapped to increase the reproductive potential of valuable domestic animals, members of endangered species, and women with fertility problems. The similarity of bovine and primate ovaries makes cattle excellent models for humans, as well as important models in themselves because of their agricultural importance. The ultimate goal of studies on the activation of primordial follicles in vitro is to develop conditions that will sustain follicular development to the stage where the oocyte is capable of meiotic maturation, fertilization and normal development.

\section{Initiation of Follicular Growth In Vitro}

The initiation of follicular growth has been achieved in titro for several species. Blandau et al. (1965) cultured fetal mouse ovaries in serum-containing medium and reported that some oocytes grew in culture, specifically those that were surrounded by one or more layers of somatic cells. Eppig and O'Brien (1996) cultured ovaries obtained from newborn mice, which contain only newly formed primordial follicles, in medium containing $10 \%$ serum for 8 days. During this interval, follicular development in vitro was qualitatively similar to development in vivo, in that some primordial follicles initiated growth and developed to the secondary stage. More remarkably, these authors then isolated growing preantral follicles from the ovaries after 8 days in culture and grew them to the stage of oocyte competence for meiotic maturation, fertilization and embryonic development. One live pup was produced after embryo transfer. These experiments showed that murine primordial follicles can initiate growth in vitro, at least in the presence of $10 \%$ serum.

Several years ago, our laboratory began experiments to determine whether bovine primordial follicles could be activated in vitro in serum-free medium. Since the large size of bovine ovaries precludes whole-organ cultures, we isolated small pieces of ovarian cortex (about $0.5 \mathrm{~mm} \times 0.5 \mathrm{~mm}$ $\times 0.3 \mathrm{~mm}$ ). Because primordial follicles are located in the cortical region of the ovary, cortical pieces are rich in primordial follicles. Since follicle formation in cattle begins in mid-gestation and fetal ovaries are much softer and easier to dissect than adult ovaries, fetuses in the third trimester of gestation were used. Pieces of cortex were cultured on transwell membrane inserts in Waymouth MB 


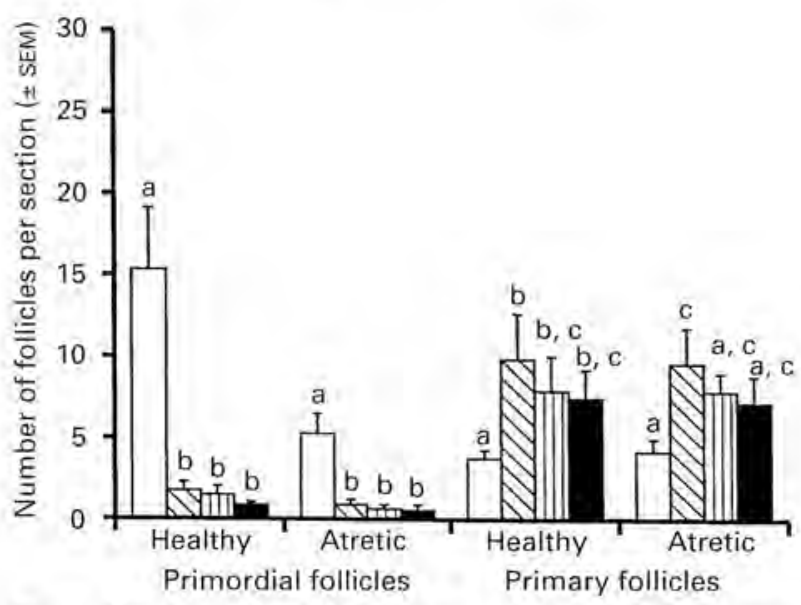

Fig. 1. Numbers of healthy and atretic primordial and primary tollicles (mean per histological section \pm SEM, $n=4$ fetuses, with 59-71 sections examined per fetus) in fetal bovine ovarian cortex after $0(\square), 2(\mathbb{D}), 4$ (III) or 7 ( days in culture. Within each group of four bars, bars with no common superscript are significantly different (a,b $P<0.01 ; a, c P<0.05)$. (Reprinted from Wandji et al, 1996b with permission.)

752/1 medium containing antibiotics and ITS+ (insulin, transferrin, selenium, BSA and linoleic acid) for up to 7 days (Wandji el al., 1996b). At the initiation of culture (day 0), the cortical pieces contained mostly primordial follicles (Fig. 1), characterized by an oocyte surrounded by a single layer of flattened granulosal cells. As early as the second day of culture the number of primordial follicles had declined markedly, whereas the number of primary follicles, characterized by a single layer of cuboidal granulosal cells, had increased (Wandji et al., 1996b). In addition, the diameter of primary follicles and their oocytes increased gradually throughout the 7 day culture (Fig. 2; Wandji ef al., 1996b). These results indicate that bovine primordial follicles can activate in vitro in serum-free medium and differentiate into primary follicles. This indicates, as the experiments with rodents had implied, that the activation of primordial follicles does not depend on specific endocrine signals. The experiments with cattle further support the contention that signals from non-cortical components of the ovary are not needed to stimulate initiation of follicle growth.

What is puzzling about the results presented in Fig. 1 is that such a large percentage of the primordial follicles in pieces of fetal bovine cortex initiated growth; almost all of them became activated in vitro. This mass exodus of follicles from the resting stage was not due to the fetal origin of the cultured cortical pieces, since Braw-Tal and Yossefi (1997) reported a similar loss of follicles from the primordial pool and an increase in primary follicles after 2 day cultures of ovarian cortical pieces from adult cattle (Table 1). Hence, something about the conditions of culture obviated the mechanisms that normally 'tell' each follicle when its 'turn' has come to leave the resting pool. The serum-free culture of ovarian cortical pieces provides a system that may be used to explore some of the factors that regulate follicle activation. Some potential regulators will be discussed below. The mass movement of follicles out of the resting pool and their development and growth as primary follicles under these experimental conditions is not unique to cattle. We have used identical methods to isolate and culture cortical pieces from ovaries from baboon fetuses and obtained similar results (Wandji et al., 1997). In addition the results of Hovatta et al. (1997) indicate that primordial follicles may activate in cultured slices of human ovarian tissue. 


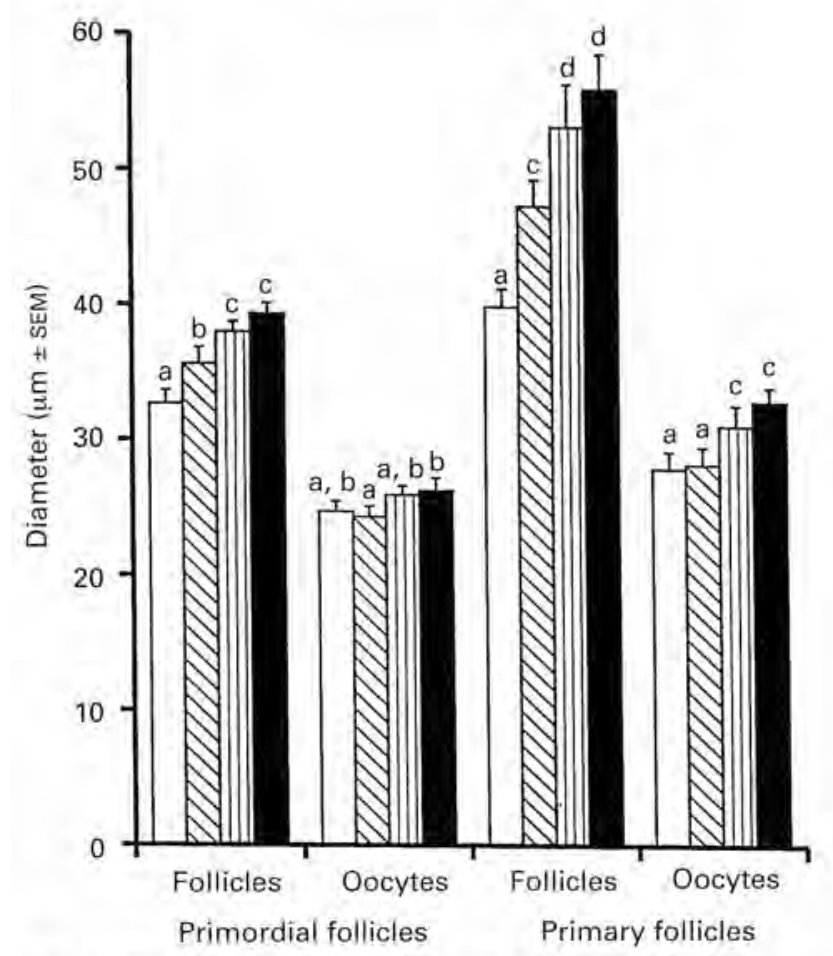

Fig. 2. Mean diameter $(\mu \mathrm{m} \pm$ SEM) of healthy primordial and primary follicles and oocytes in pieces of fetal bovine ovarian cortex after $0(\square), 2(\nabla), 4$ (III) or 7 (四) days in culture $(n=4$ fetuses, with 107-204 primordial and 231-346 primary follicles/oocytes measured per fetus). Within each group of four bars, bars with no common superscript are significantly different ( $\mathrm{a}, \mathrm{c}, \mathrm{d} P<0,01 ; \mathrm{a}, \mathrm{b} P<0,05)$. (Reprinted from Wandji et al., 1996b, with permission.)

\section{What Regulates the Activation of Primordial Follicles?}

As discussed above, experiments to date with rodent, bovine and primate ovaries show that primordial follicles can activate in whole ovaries or ovarian cortical pieces maintained in vitro even, in the case of experiments with cattle and baboons, in serum-free medium. Thus, gonadotrophins or other blood-borne factors do not appear to be necessary for initiation of follicle growth. Of interest is the observation that in cultures of whole rodent ovaries only some of the primordial follicles initiate growth in vitro, as occurs in vivo (Eppig and O'Brien, 1996), whereas in isolated pieces of bovine or baboon ovarian cortex the vast majority of primordial follicles is activated (Wandji et al., 1996b; Braw-TaI and Yossefi, 1997; Wandji et al., 1997). It is therefore possible that the more central, medullary portion of the ovary regulates the flow of primordial follicles into the pool of growing preantral follicles by secreting an inhibitory factor(s) that keeps most primordial follicles quiescent. Alternatively, the artificial reduction in the size of the pool of primordial follicles in the cortical pieces may remove some inhibitory factor(s) that normally emanates from that compartment of the ovary. There is evidence that a higher percentage of primordial follicles becomes activated if the size of the resting pool is reduced (Krarup et al., 1969; Hirshfield, 1994). Another possibility is that the conditions in vitro for cultured bovine and baboon cortical pieces are richer in some way(s) than their situation in vivo. For example, the ovarian cortex is known to be poorly vascularized (Guraya, 
Table 1. Effect of culture and FSH $\left(100 \mathrm{ng} \mathrm{ml}^{-1}\right)$ on development of bovine follicles in vitro

\begin{tabular}{|c|c|c|c|c|c|c|c|}
\hline $\begin{array}{l}\text { Day of } \\
\text { culture } \\
\text { (n) }\end{array}$ & FSH & $\begin{array}{l}\text { Primordial } \\
\text { follicles } \\
(\% \text { of total })\end{array}$ & $\begin{array}{l}\text { Primary or } \\
\text { transitory } \\
\text { follicles } \\
\text { (\% of total) }\end{array}$ & $\begin{array}{l}\text { Preantral } \\
\text { follicles } \\
(\% \text { of total) }\end{array}$ & $\begin{array}{c}\text { Follicle } \\
\text { diameter } \\
\text { (mean } \pm \text { SEM, } \mu \mathrm{m})\end{array}$ & $\begin{array}{c}\text { Oocyte } \\
\text { diameter } \\
(\text { mean } \pm S E M, \mu \mathrm{m})\end{array}$ & $\begin{array}{l}\text { Number of } \\
\text { granulosal } \\
\text { cells }\end{array}$ \\
\hline $\begin{array}{l}\theta \\
\text { (69) }\end{array}$ & - & $\begin{array}{c}50^{x} \\
(72.0)\end{array}$ & $\begin{array}{l}17^{a} \\
(25.6)\end{array}$ & $\begin{array}{l}2 \\
(2,9)\end{array}$ & $37.94 \pm 1.54^{\mathrm{a}}$ & $28.50 \pm 0.49^{a}$ & $9.81 \pm 1.48^{a}$ \\
\hline $\begin{array}{l}2 \\
(58)\end{array}$ & - & $\begin{array}{c}6^{b} \\
(10.3)\end{array}$ & $\begin{array}{c}50^{\mathrm{b}} \\
(86.2)\end{array}$ & $\begin{array}{l}2 \\
(3.4)\end{array}$ & $50.83 \pm 2.16^{b}$ & $27.91 \pm 0.52^{\circ}$ & $11.47 \pm 1.22^{i}$ \\
\hline $\begin{array}{l}2 \\
(57)\end{array}$ & + & $\begin{array}{l}3^{b} \\
(5.3)\end{array}$ & $\begin{array}{c}53^{b} \\
(93.0)\end{array}$ & $\begin{array}{c}1 \\
(1.7)\end{array}$ & $50.77 \pm 2.67^{b}$ & $27.91 \pm 0.53^{a}$ & $10.84 \pm 1.85^{\prime \prime}$ \\
\hline
\end{tabular}

Within columns, values with different superscripts are significantly different $(P<0.05)$.

$n$ : number of non-atretic follicles examined.

F Largest cross-section of the follicle.

(Reprinted with permission from Braw-Tal and Yossefi, 1997).

1985; van Wezel and Rodgers, 1996), so primordial follicles may have better access to nutrients in vitro and/or a higher oxygen concentration than in vivo.

The only specific factor that has thus far been linked to the activation of primordial follicles is kit ligand (also called stem cell factor or steel factor). Kit ligand is produced by granulosal cells, whereas primordial germ cells, oocytes and theca cells express the receptor for kit ligand, c-kit (Manova et al., 1993; Motro and Bernstein, 1993). Yoshida et al. (1997) injected mice with a function-blocking antibody to c-kit at various times during the first two weeks of life and concluded that kit ligand is needed for the activation of primordial follicles, but not for their formation. Parrott and Skinner (1997) reported that addition of kit ligand to cultures of rat ovaries induced primordial follicles to begin development, whereas an antibody that blocks the function of c-kit (the receptor for kit ligand) blocked spontaneous activation of primordial follicles. Although workers in our laboratory did not observe any effects of kit ligand on the activation of primordial follicles or subsequent growth of primary follicles (Wandji and Fortune, unpublished), in our experimental model (isolated cortex) almost all of the primordial follicles activate spontaneously. Hence further studies on the potential role of kit ligand and $\mathrm{c}-\mathrm{kit}$ in the initiation of follicle growth will be of interest.

\section{Can Follicular Growth be Maintained In Vitro?}

The previous section summarized current limited knowledge of the signals that regulate the movement of primordial follicles into the growing pool. Clearly this question is of interest if we are to understand this critical first step in follicular growth and differentiation. However, determining factors and conditions that will maintain the growth of follicles once they have been activated in vitro is also of interest. In cultures of bovine or baboon ovarian cortex, growth beyond the primary stage was rare (Wandji et al., 1996b, 1997), in contrast to the development of secondary follicles in organ cultures of whole newborn mouse or rat ovaries (Eppig and O'Brien, 1996; Mayerhofer et al, 1997). Sustained follicular growth after activation of primordial follicles in ovarian cultures from larger mammals is a necessary step if the pool of primordial follicles is to provide oocytes that can be fertilized. The sections below discuss factors or conditions which may enhance the development of small preantral follicles in vitro.

\section{Culture media}

Recently we have conducted experiments to determine whether media containing fetal bovine serum (FBS) or a combination of FBS and ITS + in various proportions would support the growth of 


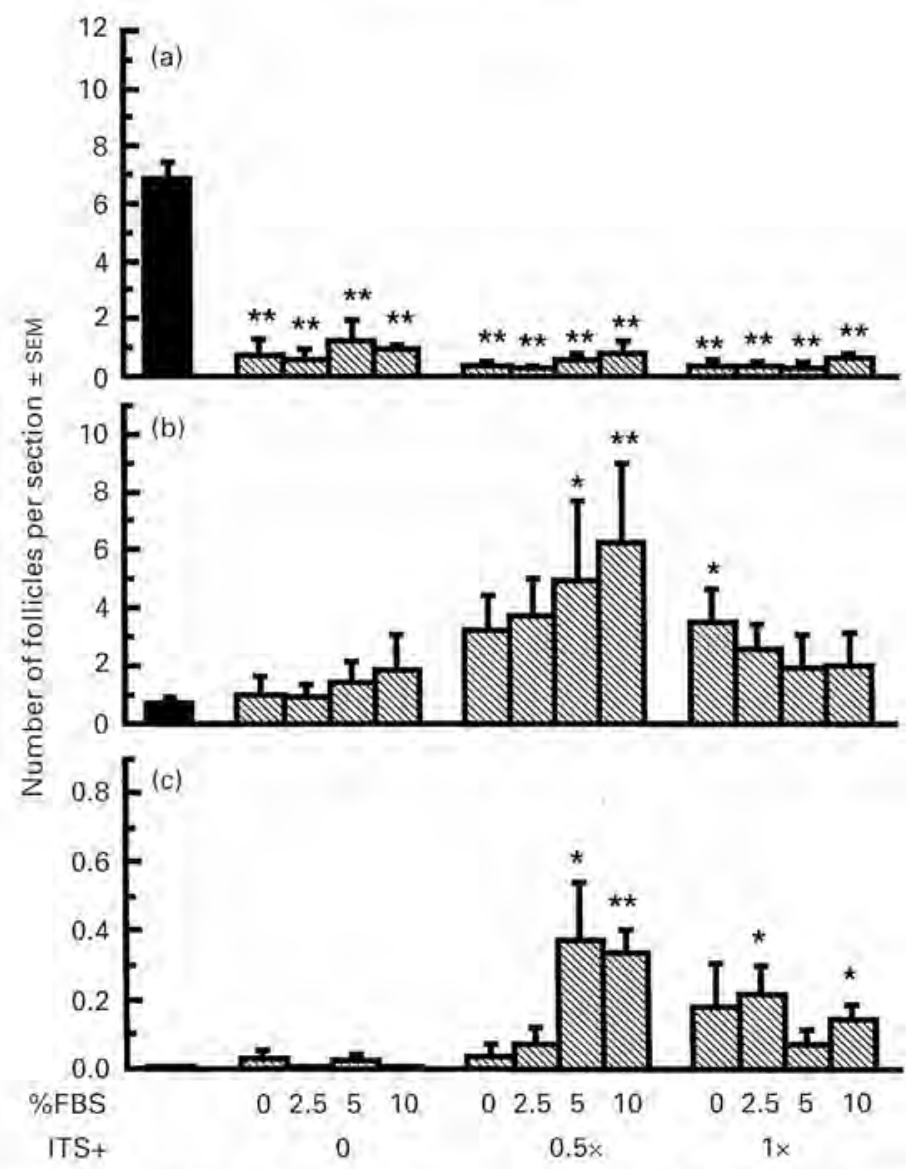

Fig. 3. Effects of culture in different media on numbers of primordial (a), primary (b) and secondary (c) follicles in pieces of fetal bovine ovarian cortex ( $n=4$ fetuses). Cortical pieces were fixed immediately after isolation (day 0 control; ) or after 10 days of culture $(\mathbb{Q})$ in $0,2.5$, 5 , or $10 \%$ fetal bovine serum (FBS) in the presence or absence of full strength $(1 \times)$ or half-strength $(0.5 x)$ ITS+ (insulin, transferrin, selenium, BSA and linoleic acid). Asterisks indicate significant differences from the day 0 control $(*, P<0.05$; **, $P<0.01)$.

secondary follicles after activation of primordial follicles. Cortical pieces from four bovine fetuses were cultured for 10 days in Waymouth MB 752/1 medium containing 0,2,5 or $10 \%$ FBS in the presence or absence of half-strength ITS $+(0.5 \times$ the normal concentration) or full-strength ITS $+(1 \times)$ and then subjected to histological morphometry and statistical analysis by methods described by Wandji et al. (1996b). The combination of $0.5 \times$ ITS + and $5 \%$ or $10 \%$ FBS was most effective, of the media tested, at supporting the growth of follicles to the primary and secondary stages (Fig.3). Surprisingly, Waymouth medium plus $10 \%$ FBS, which supports normal follicular development in newborn mouse ovaries (Eppig and O'Brien, 1996) and activates baboon oocytes without activating their granulosal cells (Wandji et al., 1997), provided a very poor environment for the activation and growth of bovine follicles. These results indicate that the type of culture medium can markedly affect the growth of follicles after activation of primordial follicles and that the optimal medium conditions may vary from species to species. 


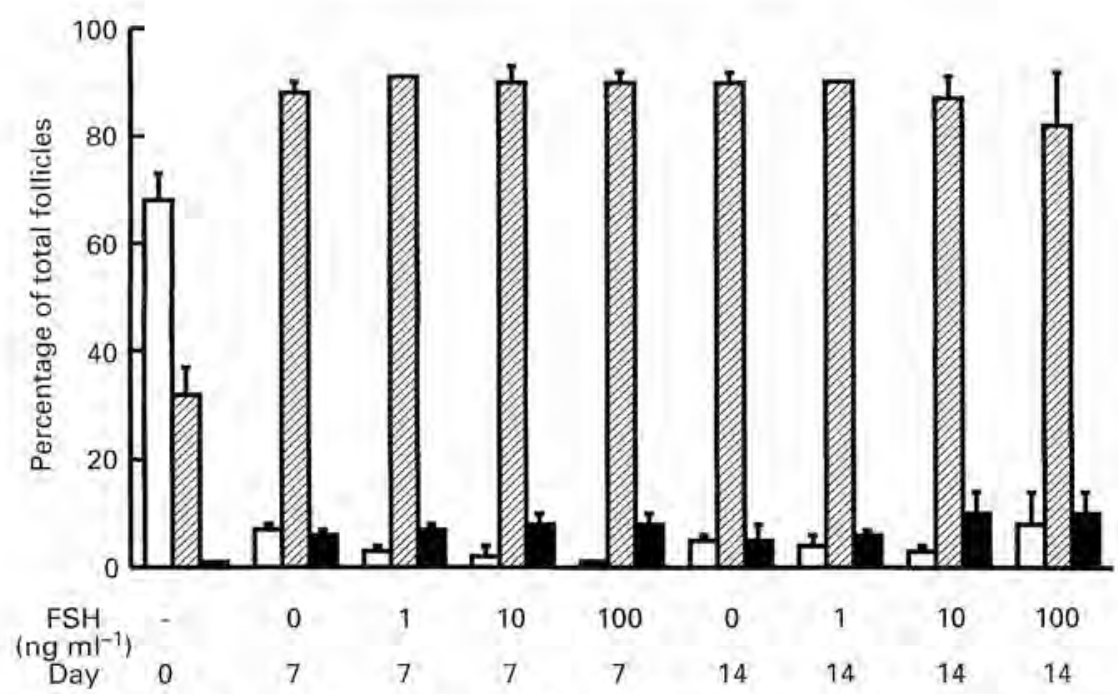

Fig. 4. Lack of effect of FSH on cultures of fetal bovine ovarian cortex. Bars indicate percentages $( \pm$ SEM) of healthy follicles that were primordial $(\square)$, primary ( $(7)$ ), or early secondary (E) stage in freshly isolated bssue or after culture with graded doses of FSH $\left(0,1,10\right.$ or $\left.100 \mathrm{ng} \mathrm{ml}^{-1}\right)$ for 7 or 14 days $(n=4$ cortical pieces, 2 from each of 2 fetuses; with 472-1232 follicles examined per treatment). (Reprinted from Fortune et al., 1998 with permission.)

FSH

The development of preantral follicles in hypophysectomized mammals (Dufour et al,, 1979; Hirshfield, 1985) indicates that gonadotrophins are not absolutely required for follicular development until the antral stage. However, since hypophysectomy reduces the number of growing preantral follicles in sheep (Dufour et al., 1979) and since bovine ovarian follicles bind FSH (Wandji et al, 1992a) and ovine follicles express messenger RNA for the FSH receptor (Tisdall et al., 1995) beginning with the primary stage, it is possible that FSH could facilitate the growth of bovine follicles in vitro, after the activation of primordial follicles. Braw-Tal and Yossefi (1997) cultured bovine cortical pieces from adult ovaries for 2 days in medium containing FSH (100 $\mathrm{ng} \mathrm{mI}^{-1}$, NIDDK oFSH-17) and found no effect on the distribution of follicles among the primordial, primary and preantral size classes (Table 1). To determine whether a longer period of exposure to FSH would induce newly activated follicles in cortical pieces from fetal bovine ovaries to develop to the secondary stage, we cultured pieces for 7 or 14 days with graded doses of FSH $(0,1,10$ or $100 \mathrm{ng} \mathrm{ml}^{-1}$; NIDDK oFSH-17). No dose of FSH had a significant effect on the distribution of follicles among the primordial, primary and secondary size classes after either 7 or 14 days of culture (Fig. 4; Fortune et al., 1998). These results are consistent with the suggestion of Wandji et al. (1992b) that the FSH receptors in fetal ovaries may not be linked to the adenylate cyclase second messenger system.

Mayerhofer et al. (1997) reported that treating neonatal rat ovaries, which contain only primordial follicles, with vasoactive intestinal peptide (VIP) or other agents that increase cAMP induced messenger RNA (mRNA) for FSH receptors. In addition, a short pretreatment with these agents induced the ovaries to become responsive to subsequent treatment with exogenous FSH in terms of cAMP secretion and in terms of follicular growth, which proceeded rapidly to the secondary stage in some follicles. To determine whether the lack of response of bovine cortical pieces to FSH that we (Fortune et al., 1998) and Braw-Tal and Yossefi (1997) had observed could be reversed by previous exposure of cortical pieces to agents that increase cyclic AMP, we replicated the 
Table 2. Cyclic AMP secretion ( $\mathrm{pg} \mathrm{h} \mathrm{h}^{-1}$ per culture \pm SEM) by pieces of bovine ovarian cortex cultured for $32 \mathrm{~h}$ ( $n=6$ cultures, 2 from each of 3 fetuses) ${ }^{a}$

\begin{tabular}{|c|c|c|c|}
\hline \multicolumn{2}{|c|}{$\begin{array}{l}\text { A. Effects of VIP or forskolin } \\
0-8 \text { h of culture }\end{array}$} & \multicolumn{2}{|c|}{$\begin{array}{l}\text { B. Effects of FSH ( } 300 \mathrm{ng} \mathrm{ml}^{-1} \text { ) } \\
8-32 \mathrm{~h} \text { of culture }\end{array}$} \\
\hline Treatment & cAMP secretion & Treatment & cAMP secretion \\
\hline Control & $\begin{array}{l}32 \pm 15^{b} \\
31 \pm 9^{b}\end{array}$ & $\begin{array}{l}\text { Control } \\
+\mathrm{FSH}\end{array}$ & $\begin{array}{l}22 \pm 4^{b} \\
34 \pm 9^{b}\end{array}$ \\
\hline VIP & $391 \pm 42^{c}$ & Control & $180 \pm 14^{d}$ \\
\hline$\left(10 \mathrm{umol} \mathrm{l}^{-1}\right)$ & $416 \pm 81^{c}$ & $+\mathrm{FSH}$ & $195 \pm 14^{d}$ \\
\hline Forskolin & $753 \pm 71^{\mathrm{c}, \mathrm{d}}$ & Control & $124 \pm 15^{d}$ \\
\hline$\left(40 \mu \mathrm{mol} \mathrm{l} \mathrm{l}^{-1}\right)$ & $792 \pm 108^{d}$ & $+\mathrm{FSH}$ & $164 \pm 38^{d}$ \\
\hline
\end{tabular}

- Each culture contained four pieces of freshly isolated, fetal ovarian cortex (approximately $0.5 \mathrm{~mm} \times 0.5 \mathrm{~mm}$ $\times 0.3 \mathrm{~mm}$ ) on a membrane insert in $350 \mu \mathrm{l}$ Waymouth MB containing ITS+ (insulin, transferrin, selenium, and BSA); medium also contained isobutyl methylxanthine, IBMX $\left(0.5 \mathrm{mmol} \mathrm{t}^{-1}\right)$ to inhibit metabolism of cAMP. bod Within columns means with no common superscript are significantly different. $b$ versus $c$ or $c$ versus $d$, $P<0.05 ;$ b versus d, $P<0.01$.

experiment of Mayerhofer et al. (1997) by treating bovine cortical pieces with VIP or forskolin for $8 \mathrm{~h}$, followed by treatment with FSH for $24 \mathrm{~h}\left(300 \mathrm{ng} \mathrm{ml}^{-1}\right.$; NIDDK oFSH-17). Media were collected and measured for CAMP by radioimmunoassay. Both VIP and forskolin increased the secretion of cAMP during the first $8 \mathrm{~h}$ of culture (Table 2). In addition, they continued to exert a 'carry-over' stimulatory effect during the next $24 \mathrm{~h}$. However, FSH did not increase the secretion of cAMP whether or not tissue had been pretreated with VIP or forskolin. These results suggest that, at least under the conditions used, a short exposure to increased CAMP is not sufficient to induce functional FSH receptors and a cAMP response to FSH in bovine ovarian cortex, in contrast to the results for neonatal rat ovaries (Mayerhofer et al., 1997). Therefore, it appears that the addition of FSH to cultures of bovine primary follicles grown in vitro is not useful. However, FSH does have effects on cultures of larger preantral follicles from mice (Eppig and O'Brien, 1996; Cortvrindt et al., 1997). Therefore, if methods can be devised for growing bovine follicles to later preantral stages, FSH could then be tested for facilitation of further growth in vitro of larger preantral follicles.

\section{Other factors: growth factors (GDF-9, bFGF), activin, WT1}

Several hormones and growth factors have been implicated indirectly in early follicular development. It would be of interest to determine whether one or more of these agonists could stimulate the growth of follicles activated in vitro to the early secondary stage and beyond. Growth differentiation factor 9 (GDF-9), a member of the transforming growth factor- $\beta$ superfamily, is of particular interest since mRNA for GDF-9 is found only in oocytes from the primary follicle stage through ovulation. In mice homozygous for a GDF-9 'knockout', follicles were activated but did not proceed beyond the primary stage (Dong et al., 1996), indicating that production of GDF-9 by the oocyte is critical for follicular development after the primary stage. Basic fibroblast growth factor (bFGF) is also of interest. Van Wezel et al. (1995) immunolocalized bFGF to bovine primordial and primary oocytes and suggested a role for this growth factor in stimulating granulosal cell proliferation. This hypothesis is consistent with experiments that showed that the binding of radiolabelled bFGF to bovine follicle cells is highest in the preantral stages, including primary follicles (Wandji et al., 1992c) and that bFGF stimulates thymidine incorporation into bovine granulosal cells of preantral follicles in vitro (Wandji et al., 1996a).

Activin A markedly stimulated the growth of preantral follicles $(100-120 \mu \mathrm{m}$ in diameter) and synergized with FSH when follicles were obtained from immature mice, but not adult mice (Yokota et al., 1997). Tisdall et al. (1995) detected mRNA for $\beta_{\mathrm{B}}$ inhibin (needed for synthesis of activin B) as 
early as the primary stage of ovine follicular development. Finally Wilms' tumour gene, WT1, is a gene deleted in some Wilms' tumours that codes for a transcription factor; its mRNA is expressed strongly in the early stages of rat preantral follicular development (Hsu et al., 1995). What role(s) activin or WT1 may play in early follicular development remains to be elucidated.

\section{Conclusions}

Primordial follicles of rodents, cattle and primates can be activated in vitro to begin growth. In the experiments conducted thus far, the culture of intact whole ovaries results in the activation of an approximately normal number of primordial follicles and some of them grow to the multilayered secondary stage within a few days to a week of culture (Eppig and O'Brien, 1996; Mayerhofer et al., 1997). In contrast, in isolated pieces of ovarian cortex from cattle and primates most primordial follicles initiate growth, but few follicles proceed to the secondary stage (Wandji et al., 1996b, 1997; Fortune et al., 1998). These findings raise interesting questions about what regulates the activation of primordial follicles in vivo. Although preliminary evidence implicates kit ligand as a stimulator of primordial follicle activation (Parrott and Skinner, 1997), the results also suggest that an inhibitor(s) is involved. The development of conditions in vitro that will allow the development of ruminant and primate follicles activated in vitro to a size where they might be isolated for further culture is essential to achieve the goal of producing embryos from the reservoir of primordial follicles. A number of laboratories have cultured larger preantral follicles (for review see van den Hurk et al., 1997) and their experience will be helpful in developing culture strategies for large preantral follicles grown in vitro, if methods can be devised for getting them to that stage. Thus far one live mouse has been produced from a primordial follicle (Eppig and $\mathrm{O}^{\prime}$ Brien, 1996). This shows that it is possible to use the primordial pool as a source of oocytes to produce embryos, but the difficulties of doing so will be much greater in ruminants and primates because of the larger size and longer developmental period of their oocytes. Some progress has been made towards the goal, but much more remains to be done. However, recent reports of follicle growth in vitro or production of live offspring after cryopreservation of rodent or human ovarian tissue (Carroll and Gosden, 1993; Hovatta et al., 1997; Sztein et al., 1998) indicate that the 'banking' of frozen ovarian tissue from valuable domestic animals, endangered species or women scheduled for radiation or chemotherapy, coupled with the ability to produce embryos from primordial follicles, would provide a powerful method for enhancing fertility in these groups.

The contributions of Drs Wandji, Voss and Srsen, Ms Hansen, Ms Bartholomew and Mr Murphy, to the experiments presented in Figs 1,2 and 3 and Table 2 are gratefully acknowledged. The unpublished data presented herem were generated through the support of the NIH (HD-35168 to J. E. Fortune). The NIDDK generously provided the oFSH and Taylor Packing Inc. (Wyalusing, PA) donated the fetal bovine ovaries used in those studies.

\section{References}

Blandau RJ, Warrick E and Rumery RE (1965) In vitro cultivation of fetal mouse ovaries Fertility and Sterility 16 705-715

Braw-Tal R and Yossefi S (1997) Studies in vivo and in vitro on the initiation of follicle growth in the bovine ovary Journal of Reproduction and Fertility 109 165-171

Carroll J and Gosden RG (1993) Transplantation of frozenthawed mouse primordial follicles Human Reproduction 8 1163-1167

Cortvrindt R, Smitz J and Van Steirteghem AC (1997) Assessment of the need for follicle stimulating hormone in early preantral mouse follicle culture in vitro. Human Reproduction $12759-768$

Dong I, Albertini DF, Nishimori $\mathrm{K}$, Kumar TR, Lu $\mathrm{N}$ and
Matzuk MM (1996) Growth differentiation factor-9 is required during early ovarian folliculogenesis Nature 383 531-535

Dufour J, Cahill LP and Mauleon P (1979) Short- and long-term effects of hypophysectomy and unilateral ovariectomy on ovarian follicular populations in sheep joumal of Reproduction and Fertility 57 301-309

Eppig II and O'Brien MJ (1996) Development in vitro of mouse oocytes from primordial follicles Biology of Reproduction 54 197-207

Fortune JE; Kito S, Wandji S-A and Srsen V (1998) Activation of bovine and baboon primordial follicles in vitro. Theriogenology 49 441-449 
Guraya SS (1985) Primordial follicle. In Biology of Ovarian Follicles in Mamnals pp 3-14 Springer-Verlag, New York

Henricson B and Rajakoski E (1959) Studies of oocytogenesis in cattle Cornell Veterinarian 49 494-503

Hirshfield AN (1985) Comparison of granulosa cell proliferation in small follicles of hypophysectomized, prepubertal, and mature rats Biology of Reproduction 32 979-987

Hirshfield AN (1991) Development of follicles in the mammalian ovary International Retriew of Cytology 124 43-101

Hirshfield AN (1994) Relationship between the supply of primordial follicles and the onset of follicular growth in rats Biology of Reproduction 50 421-428

Hovatta O, Silye R, Abir R, Krausz. T and Winston RML (1997) Extracellular matrix improves survival of both stored and fresh human primordial and primary ovarian follicles in long-term culture Human Reproduction 12 1032-1036

Hsu SY, Kubo M, Chun S-Y, Haluska FG, Housman DE and Hsueh AJW (1995) Wilms tumor protein WTI as an ovarian franscription factor: decreases in expression during follicle development and repression of inhibin- $\alpha$ gene promoter Molecular Endocrinology/ 9 1356-1366

Krarup T, Pedersen T and Faber M (1969) Regulation of oocyte growth in the mouse ovary Nature 224 187-188

Manova K, Huang EI, Angeles M, De Leon V, Sanchez S, Pronovost SM, Besmer P and Bachvarova RF (1993) The expression pattern of the c-kit ligand in gonads of mice supports a role for the c-kit receptor in oocyte growth and in proliferation of spermatogonia Developmental Biology 15785 -99

Mayerhofer A, Dissen GA, Costa ME and Ojeda SR (1997) A role for neurotransmitters in early follicular development: induction of functional follicle-stimulating hormone receptors in newly formed follicles of the rat ovary Endocrinology 138 3320-3329

Motro B and Bernstein A (1993) Dynamic changes in ovarian c-kit and Steel expression during the estrous reproductive cycle Developmental Dymamics 197 69-79

Parrott JA and Skinner MK (1997) Theca cell-granulosa cell interactions that induce primordial follicle development and promote folliculogenesis Biology of Reproduction 56, Supplement 1125

Russe I (1983) Oogenesis in cattle and sheep Bibliolhecn Anatomica 24 77-92

Sztein J, Sweet H, Farley J and Mobraaten L (1998) Cryopreservation and orthotopic transplantation of mouse ovaries: new approach in gamete banking Biology of Reproduction 58 1071-1074

Tisdall DJ, Smith P, Leeuwenberg B and McNatty KP (1995) FSH-receptor, $b_{B}$ inhubin subunit, follistatin, $\beta_{A}$ and $\alpha$ inhibin subunits and IGF-I genes are expressed sequentially in ovine granulosa cells during early follicular development Journal of Reproduction and Fertility Abstract Series 15 Abstract 28

van den Hurk R, Bevers MM and Beckers JF (1997) In-vivo and in-vitro development of preantral follicles Theriogenology 47 73-82

van Wagenen G and Simpson ME (1965) Embryology of the Ovary and Testis: Homo sapiens and Macaca mulatta Yale University Press, New Haven

van Wezel IL and Rodgers RJ (1996) Morphological characterization of bovine primordial follicles and their environment in vivo, Biology of Reproduction 55 1003-1011

van Wezel IL, Umapathysivam K, Tilley WD and Rodgers RJ (1995) Immunohistochemical localization of basic fibroblast growth factor in bovine ovarian follicles Molecular and Cellular Endocrinology 115 133-140

Wandji S-A, Pelletier G and Sirard M-A (1992a) Ontogeny and cellular localization of ${ }^{125} \mathrm{I}$-labeled insulin-like growth factor-I, ${ }^{22}$ - -labeled follicle-stimulating hormone, and 129-labeled human chorionic gonadotropin binding sites in ovaries from bovine fetuses and neonatal calves Biology of Reproduction 47 814-822

Wandji S-A, Fortier MA and Sirard M-A (1992b) Differential response to gonadotropins and prostaglandin $\mathrm{E}_{2}$ in ovarian tissue during prenatal and postnatal development in cattle Biology of Reproduction 46 1034-1041

Wandji S-A, Pelletier G and Sirard M-A (1992c) Ontogeny and cellular localization of ${ }^{125}$-labeled basic fibroblast growth factor and ${ }^{25} \mathrm{I}$-labeled epidermal growth factor binding sites in ovaries from bovine fetuses and neonatal calves Biology of Reproduction 47 807-813

Wandji S-A, Eppig J] and Fortune JE (1996a) FSH and growth factors affect the growth and endocrine function in vitro of granulosa cells of bovine preantral follicles Theriogenology $45817-832$

Wandji S-A, Srsen V, Voss AK, Eppig JJ and Fortune IE (1996b) Initiation in vitro of growth of bovine primordial follicles Biology of Reproduction 55 942-948

Wandji S-A, Srsen V, Nathanielsz PW, Eppig JJ and Fortune JE (1997) Initiation of growth of baboon primordial follicles in vitro. Human Reproduction 12 1993-2001

Yokota H, Yamada K, Liu X, Kobayashi J, Abe $\mathrm{X}$, Mizunuma $\mathrm{H}$ and Ibuki Y (1997) Paradoxical action of activin A on folliculogenesis in immature and adult mice Endocrinology $1384572-4576$

Yoshida H, Takakura N, Kataoka H, Kunisada T, Okamura $\mathrm{H}$ and Nishikawa S-I (1997) Stepwise requirement of c-kit tyrosine kinase in mouse ovarian follicle development Developmental Biology 184 122-137 